\title{
O Que Pensam os Professores a Respeito do Problem Based Learning como Estratégia de Ensino na Contabilidade?
}

\author{
Elisabeth de Oliveira Vendramin*1, João Paulo Resende de Lima², Raíssa Silveira de Farias ${ }^{1}$, \\ Adriana Maria Procópio de Araujo ${ }^{3}$ \\ ${ }^{1}$ Doutoranda em Controladoria e Contabilidade na Faculdade de Economia, Administração e Contabilidade de \\ Ribeirão Preto da Universidade de São Paulo \\ 2Doutorando em Controladoria e Contabilidade na Faculdade de Economia, Administração e Contabilidade da \\ Universidade de São Paulo \\ ${ }^{3}$ Professora Titular do Departamento de Contabilidade - Faculdade de Economia, Administração e Contabilidade \\ de Ribeirão Preto da Universidade de São Paulo
}

* Autora para correspondência: elisabethov@usp.br

\section{RESUMO}

O objetivo deste estudo é apresentar a percepção docente a respeito da utilização da estratégia de ensino Problem Based Learning (PBL) em cursos de Contabilidade. O foco no docente justifica-se com base na afirmação de Martins e Espejo (2015) de que o docente é um dos três elementos principais da metodologia, contudo são poucos os estudos que o abordam. Para alcançar o objetivo proposto foi adotada a abordagem qualitativa de pesquisa por meio de entrevistas semiestruturadas com quatro docentes. A seleção dos participantes ocorreu de forma não probabilística e intencional, pois o foco do trabalho exigiu que o docente estivesse inserido em curso de Ciências Contábeis e já tenha utilizado a estratégia PBL. O guia de entrevista, desenvolvido com base no trabalho de Grishan, Martiniul, Negin e Wright (2015), abrange três tópicos principais: (i) identificação do participante; (ii) primeiro contato; e (iii) utilização do PBL. O principal resultado do estudo indicou uma falha na formação pedagógica do docente, resultado que corrobora estudos anteriores. Os entrevistados foram unânimes ao dizer que conheceram o PBL somente após começarem a atuar como docentes, o que auxilia na justificativa da divergência de opiniões a respeito de qual é o papel do docente perante o PBL, o que pode colocar em xeque os benefícios da utilização do método.

Palavras-Chave: Problem Based Learning; Estratégia de Ensino; Estratégia de Aprendizagem; Ensino Superior; Contabilidade.

\begin{abstract}
The purpose of this study is to present a teacher perception about the use of the Problem Based Learning (PBL) teaching strategy in Accounting courses. The teaching focus is justified based on Martins and Espejo's (2015) statement that defines the teacher as one of the main topics of the methodology, however, there are few studies that approach. A qualitative research approach was adopted through semi-structured interviews with four teachers. The selection of the participants was not a probabilistic and intentional practice, since the focus of the work requires that the teacher is involved in the Accounting Sciences course and have already used a PBL strategy. The interview guide was developed based on the work of Grishan, Martiniul, Negin and Wright (2015) with the following main topics: (i) identification of the participant; (ii) first contact; and (iii) use of the PBL. The main result of the study indicated a failure in the pedagogical formation of the teacher, a result that corroborates previous studies. The interviewees were unanimous in saying that they had contact with the PBL only after they started to work as teachers, which helps to justify the divergence of opinions regarding the role of the teacher in the PBL, a finding that can put the benefits the use of the method.
\end{abstract}

Keywords: Problem Based Learning; Teaching strategy; Higher education; Accounting. 


\section{Introdução}

Atualmente o ensino superior no Brasil é legislado pelo Conselho Nacional de Educação (CNE), que possui orientações específicas para cada área do conhecimento. A área de Ciências Contábeis segue as orientações contidas nas diretrizes curriculares nacionais expostas na Resolução CNE/CES n. 10, de 16 de dezembro de 2004. Especificamente sobre o perfil profissional esperado para o formando, a resolução apresenta oito habilidades e competências que devem ser desenvolvidas durante o curso, sendo essas relacionadas com conhecimentos específicos da área e com o uso das técnicas contábeis pelo futuro profissional. Entretanto, o item ii) desse artigo afirma que o profissional deve demonstrar visão sistêmica e interdisciplinar da atividade contábil, de forma que conheça o ambiente social e interaja com ele. Assim, o desafio a ser enfrentado pelas IES é aliar o conhecimento técnico, fortemente exigido, com o desenvolvimento de habilidades e competências de caráter humanista, ético e dinâmico, para não apenas satisfazer seu Projeto Político-Pedagógico (PPP), mas também atender novas demandas do mercado de trabalho (MARTINS \& ESPEJO, 2015).

Devido às mudanças sofridas no mercado de trabalho, os profissionais contábeis estão cada vez mais ocupando posições que exigem atitudes para resolução de problemas nas organizações, de maneira que o perfil desses profissionais deve ser compatível com o mercado e com as mudanças organizacionais (ARAUJO \& SLOMSKI, 2013; MARIN, et al., 2014). Mitre et al. (2008) afirmam que na graduação é essencial utilizar uma metodologia que contemple uma prática educacional libertadora, que forme um profissional ativo e apto a aprender a aprender, já que o curso de graduação dura alguns anos, enquanto a prática profissional perdura por décadas. Quando o discente aprende a aprender, ele se torna capaz de se adaptar a essas mudanças.

Cabe ao professor universitário estar capacitado em termos pedagógicos para direcionar sua disciplina de forma a alcançar o objetivo de desenvolver o conjunto de habilidades e competências pensadas e descritas no PPP. Para Berbel (2011, p. 26), "o professor é o grande intermediador desse trabalho, e ele tanto pode contribuir para a promoção de autonomia dos alunos como para a manutenção de comportamentos de controle sobre os mesmos". Nesse contexto inserem-se as discussões sobre o uso de metodologias ativas: técnicas utilizadas no processo de aprendizagem que objetivam colocar o estudante em uma posição central e proativa (ARAUJO \& SLOMSKI, 2013) que abre possibilidades de ele evoluir de um discente com consciência ingênua para um discente com consciência crítica (MITRE et al., 2008).

Dentre as várias metodologias ativas existentes, esse estudo vai tratar especificamente da estratégia de ensino Problem Based Learning (PBL), ou na tradução para o português, Aprendizagem Baseada em Problemas (ABP). É uma estratégia de ensino caracterizada pelo uso de problemas reais visando a desenvolver habilidades de resolução de problemas, pensamento crítico e conceitos importantes da área de conhecimento em que se insere (RIBEIRO, 2005). Segundo Martins e Espejo (2015), dentro do PBL há três elementos centrais: $\mathrm{o}$ aluno, o problema e o professor. Diversos estudos foram realizados com foco no aluno (RODRIGUES \& ARAUJO, 2007; SOARES, et al., 2008; SIQUEIRA, et al., 2009; BENJAMIN JR. \& CASA NOVA, 2012), demonstrando assim uma necessidade de trabalhos que foquem nos outros dois elementos essenciais da metodologia.

Neste contexto o presente trabalho tem por objetivo apresentar a percepção docente a respeito da utilização da metodologia PBL como estratégia de ensino nos cursos de ciências contábeis.

\section{Problem Based Learning como Metodolo- gia de Ensino}

O ensino superior no Brasil é caracterizado pelo uso de metodologias tradicionais, por meio das quais o conhecimento é transmitido pela figura do docente, visto como o detentor do conhecimento e figura central no processo de ensino. $\mathrm{O}$ discente, por sua vez, é um sujeito passivo nesse processo, 
assumindo o papel de espectador, de quem não se faz necessária uma reflexão crítica a respeito do conteúdo ministrado (MITRE et al., 2008). Entretanto, o mercado exige cada vez mais um profissional com senso crítico e rápida adaptação às mais diversas situações. Assim, o desafio a ser enfrentado pelas IES é aliar o conhecimento técnico, fortemente exigido, com o desenvolvimento de habilidades e competências de caráter humanista, ético e dinâmico para não apenas realizar seu PPP, mas também atender novas demandas do mercado de trabalho (MARTINS \& ESPEJO, 2015).

Nesse sentido, inserem-se as discussões sobre o uso de metodologias ativas, sendo que essas técnicas utilizadas no processo de aprendizagem requerem do estudante uma postura ativa pautada por com curiosidade criativa, questionadora e sempre insatisfeita (MITRE et al., 2008).

Dentre as metodologias ativas, o PBL é uma estratégia de ensino caracterizada "pelo uso de problemas da vida real para estimular o desenvolvimento de pensamento crítico e habilidades de solução de problemas e a aprendizagem de conceitos fundamentais da área de conhecimento em questão" (RIBEIRO, 2005). A metodologia teve sua origem registrada em meados dos anos 1960, no Canadá, especificamente na McMaster University Medical School. Atualmente tem sido bastante utilizada nos cursos de medicina (SOARES et al., 2008).

O PBL é uma estratégia de ensino centrada na discussão de problemas em grupo, cujo objetivo é apontar solução para os mesmos. Um dos fundamentos do PBL é forçar que o aluno busque o aprendizado ao acessar fontes diversas de conhecimento, extrapolando os limites do que é transmitido pelo professor. Esses conhecimentos são necessários para que a discussão flua e o grupo alcance uma solução para o problema apresentado (SOARES et al., 2017). Conforme Martins e Espejo (2015, p. 58), "problemas complexos são abordados com o intuito de motivar os alunos a identificarem e pesquisarem os conceitos e princípios que eles precisam saber para trabalhar com tais problemas".
Para Martins e Espejo (2015), o ponto de partida do PBL é a apresentação do problema aos alunos e a formação de grupos de trabalho permanentes, organizados para discutir e solucionar o problema. Soares et al. (2017) defendem que em cada grupo devem existir três papéis: um secretário/relator; um líder/coordenador; e membros do grupo. O secretário ficará responsável pela parte de organização e apontamentos de todas as discussões. O líder deve coordenar o grupo, incentivar todos a participarem, manter o foco da discussão e controlar o tempo. Os demais membros devem colaborar com o secretário e com o líder, bem como se envolver ativamente na leitura, pesquisa e resolução do problema proposto.

Soares et al. (2017) apresentam sete passos do PBL: i) apresentação da situação-problema, com esclarecimento de termos; ii) identificação do problema; iii) tentativa de resolução com conhecimento disponível e discussão dos problemas; iv) resumo da discussão; v) questões de estudo e objetivos de aprendizado; vi) tentativa de resolução com conhecimento disponível e discussão dos problemas; vii) integração das informações e resolução dos problemas.

Enquanto os grupos trabalham e se envolvem na resolução do problema, o docente tem a função de: manter o fluxo das discussões, estimular, fazer perguntas, prover informações, observar e analisar e dar feedback aos grupos (SOARES et al., 2017).

Para que o ensino superior em contabilidade atinja o objetivo de desenvolver habilidades e competências de caráter humanista, ético e dinâmico, o método PBL pode ser utilizado com o intuito de contribuição para com esse propósito, já que é um método desenvolvido em grupo, que cria um ambiente que estimula os alunos a buscarem soluções teóricas e práticas para os problemas propostos, e, assim, auxilia o pensamento crítico do discente. Os problemas propostos pelo método PBL envolvem a prática, o ensino e a pesquisa; dessa forma, o método aproxima os estudos da realidade que os mesmos vão encontrar ao finalizarem o ensino superior e se colocarem no mercado de trabalho. 


\section{A Utilização do Problem Based Learning no Brasil}

No Brasil, a pesquisa a respeito da utilização do PBL na contabilidade teve início com o trabalho de Rodrigues e Araujo (2007). O trabalho desenvolvido pelas autoras visava a verificar a aplicabilidade do método no curso de ciências contábeis e mensurar a aceitação do método por parte dos alunos. Os resultados de Soares, Araujo e Leal (2008), seguindo a linha de estudos com foco no aluno, apontam que os estudantes adquiriram o conhecimento de forma satisfatória, cumpriram as etapas propostas e demonstraram alta aceitação.

Siqueira et al. (2009) realizaram um estudo qualitativo em que entrevistaram quinze alunos para analisar a aplicabilidade do PBL. Dentre os resultados destaca-se a percepção dos alunos de que existe uma mudança de postura - de simples receptor das informações para discente ativo em conformidade com diferentes graus de autonomia. Apesar das vantagens da metodologia, oito discentes (53\%) levantaram possíveis restrições de sua aplicação, ligadas principalmente ao papel dos tutores e a um sentimento de insegurança.

Já Araujo et al. (2010) relataram o uso da metodologia em um curso de pós-graduação lato sensu e sua efetividade. $\mathrm{O}$ trabalho mostra que, na visão dos alunos, a metodologia é adequada para o nível de ensino e que os conhecimentos adquiridos por meio dela são superiores aos adquiridos por meio da aula expositiva.

Benjamin Jr. \& Casa Nova (2012) apontam que há melhor desempenho dos alunos após a aplicação do PBL e que os próprios discentes percebem vantagens no seu uso, principalmente no que tange ao desenvolvimento de competências e habilidades. Entretanto, os autores advertem que a metodologia deve ser um complemento da aula tradicional, e não um substituto.

Martins \& Frezatti (2015) apresentam e discutem diferentes modalidades - OneDay; One-problem; Project Based Learning e Case-Based - do PBL e as vantagens e desvantagens de cada modalidade. Os autores ressaltam a divergência da literatura a respeito dos aspectos estruturais da metodologia e que sua aplicação deve considerar a maturidade dos discentes, a complexidade do problema, o objetivo e o tempo disponível para aplicação.

\section{O Papel do Docente na Utilização do Pro- blem Based Learning}

Historicamente, o ensino da contabilidade está estruturado com base no processo de ensino - caraterizado pela situação em que o docente ensina aos alunos que não sabem e estes por sua vez reproduzem as informações recebidas; caracterizado por ações como instruir, ensinar, orientar, mostrar, guiar etc., que colocam o docente como o principal agente. Entretanto, existe o processo de aprendizagem - acontece por meio de ações como buscar informações, rever a experiência, adquirir habilidades etc., que são ações centradas no discente (MASETTO, 2012). Assim, o docente nos métodos tradicionais de ensino é visto com o papel de transmissor do conhecimento, e o discente é um agente passivo e apenas recebe esse conhecimento e o reproduz em momento oportuno. Já os métodos ativos de aprendizagem exigem do docente uma postura diferente, inclinada a ser ele um facilitador do processo de aprendizagem.

Cabe destacar que os docentes dos cursos de contabilidade são, em sua maioria, bacharéis em contabilidade, ou seja, não receberam formação pedagógica para atuarem como docentes, como é o caso dos cursos de licenciatura. Essa falta de formação pedagógica deveria ser suprida por meio da pós-graduação. Estudos mostram que os cursos de pós-graduação stricto sensu na área de Contabilidade estão formando pesquisadores e não professores (ANDERE \& ARAUJO, 2008; SLOMSKI et al., 2014; LIMA et al., 2015).

Dessa forma, o cenário em que se encontra atualmente o ensino superior em Ciências Contábeis é o de replicação de exemplos de docentes que o atual professor teve durante a sua formação, o que explica a utilização predominante da aula expositiva, na qual o docente é transmissor de conhecimento. A questão que surge é: como um professor que exerce o papel de facilitador no processo de ensino 
- mesmo sem formação para isso - vai passar a exercer o papel de facilitador no processo de aprendizagem, ainda sem formação pedagógica para tal? Essa transição demanda esforço extra do docente: procura por cursos da área pedagógica, leituras, estudos, e sabemos que, na maioria das vezes, o professor não dispõe desse tempo.

Um docente facilitador instiga os alunos por meio de atividades reflexivas, de forma que eles próprios descubram as suas necessidades de aprendizagem (MARTINS \& ESPEJO, 2015).

\section{Metodologia}

Para atingir o objetivo da pesquisa, foi adotada a abordagem qualitativa de pesquisa, e para a construção de evidências foram realizadas entrevistas semiestruturadas com quatro docentes, duas via Skype e duas presencialmente, com duração média de 45 minutos cada. A seleção dos participantes ocorreu de forma não probabilística e intencional, pois o foco do trabalho exigiu que o docente estivesse inserido em curso de Ciências Contábeis e já tenha utilizado o PBL. O guia de entrevista, desenvolvido com base no trabalho de Grishan et al. (2015), abrange três tópicos principais: (i) identificação do participante; (ii) primeiro contato; e (iii) utilização do PBL.

Para a avaliação dos dados, adotou-se a análise de conteúdo, sendo esta "uma técnica de pesquisa que trabalha com a palavra, permitindo de forma prática e objetiva produzir inferências do conteúdo da comunicação de um texto replicáveis ao seu contexto social" (CAREGNATO \& MUTTI, 2006, p. 682).

\section{Identificação dos Participantes}

Para iniciar a entrevista, foram apresentados o propósito da pesquisa e em seguida as perguntas que fazem parte do primeiro tópico de questionamento - identificação dos participantes. O quadro 1 traz de maneira resumida as respostas desse primeiro bloco de questionamentos.

Na sequência foi questionado se os participantes conheciam alguma metodologia ativa e se já a haviam utilizado. Os quatro docentes afirmaram conhecer algumas - especialmente o PBL. Apesar de conhecerem algumas metodologias ativas, Pedro e Tatiana ressaltam que não sabem o conceito por detrás destas, o que é sugestivo de falha na sua formação para docência, como pode ser visto nas seguintes falas:

Faço ideia de que, pela abordagem, o PBL seja uma delas [metodologias ativas], mas confesso não ter nenhum conhecimento conceitual do que sejam. (Pedro)

Bom, eu não sei bem se eu sei o que é uma metodologia ativa, mas eu sei que o PBL é uma metodologia ativa de aprendizagem. (Tatiana)

\begin{tabular}{|l|l|l|l|}
\hline Identificação & $\begin{array}{l}\text { Tempo de } \\
\text { Docência }\end{array}$ & \multicolumn{1}{|c|}{ Formação } & Linha de Atuação \\
\hline Pedro & 10 anos & $\begin{array}{l}\text { Doutorado em Controladoria } \\
\text { e Contabilidade }\end{array}$ & $\begin{array}{l}\text { Contabilidade Financeira e } \\
\text { Pública }\end{array}$ \\
\hline Tatiana & 13 anos & $\begin{array}{l}\text { Doutorado em Controladoria } \\
\text { e Contabilidade }\end{array}$ & $\begin{array}{l}\text { Contabilidade Financeira e } \\
\text { Aplicada ao Terceiro Setor }\end{array}$ \\
\hline Aurora & 18 anos & $\begin{array}{l}\text { Doutorado em Controladoria } \\
\text { e Contabilidade }\end{array}$ & Finançase Educação Contábil \\
\hline Beatriz & 16 anos & Doutorado em Administração & $\begin{array}{l}\text { Contabilidade Gerencial e } \\
\text { Educação Contábil }\end{array}$ \\
\hline
\end{tabular}

Quadro 1 - Identificação e caracterização dos respondentes. 
Visto que já haviam aplicado o PBL, os quatro docentes foram questionados a respeito de como conheceram a metodologia. Pedro afirma ter conhecido o PBL quando fez parte da comissão coordenadora do curso, por meio de uma sugestão de outro docente do mesmo departamento enquanto discutiam as especificidades e dificuldades de ensinar contabilidade. Já Tatiana e Beatriz conheceram a metodologia quando auxiliaram o desenvolvimento de um trabalho acadêmico sobre o tema. Por fim, Aurora entrou em contato com a metodologia ao cursar uma disciplina, como aluna especial, em um programa de pós-graduação em educação. Esses resultados podem ser comparados com os de Farias \& Araujo (2016), que mostraram que os docentes de Ciências Contábeis acreditam que recebem uma formação básica para a atuação docente no decorrer da pós-graduação, contudo adquirem mais conhecimentos por conta própria ao longo de sua carreira.

\section{Primeiro Contato e Utilização do PBL}

No segundo bloco de questionamentos, o foco era a utilização do PBL pelos quatro docentes entrevistados. Inicialmente os participantes foram questionados se haviam participado de algum treinamento específico da metodologia. Pedro e Aurora não receberam nenhum treinamento para a aplicação, ao contrário de Tatiana e Beatriz, que tiveram um treinamento anterior à aplicação, para garantir a qualidade da aplicação com o intuito de auxiliar no desenvolvimento da pesquisa de que participaram.

Um ponto levantado pelos quatro docentes foi a leitura de trabalhos a respeito do tema, ressaltando assim a importância de estudos e materiais didáticos de qualidade. Ainda a respeito dos treinamentos, Aurora afirma que auxiliou outro docente durante uma aplicação antes de utilizar o PBL sozinha. A docente destacou ainda que aprofundou seus conhecimentos sobre a metodologia ao auxiliar a organização de um workshop da metodologia com o intuito de divulgá-la e fornecer treinamento a outros professores que desejassem aplicar PBL em suas aulas.
Quando questionados a respeito do PBL, quanto ao nível de ensino e ao tempo utilizado, vê-se a aplicação tanto na graduação, quanto na pós-graduação stricto sensu e lato sensu. Na aplicação nos cursos de graduação, Pedro costuma utilizá-lo durante seis horas de uma disciplina de sessenta horas, enquanto Tatiana o utiliza por doze horas e Beatriz numa média de dez horas, ambas em disciplinas de carga horária de sessenta horas.

Em sua fala Beatriz demonstra que, na sua percepção, o mínimo para aplicação seriam três aulas de cem minutos. Ela afirma que esse tempo é necessário, pois devem ser seguidos todos os "passos da preparação, divisão do grupo, escolher o líder e o secretário [...]". A docente ressalta ainda que "tinha momentos também em que eu ficava em sala e os grupos não precisavam estar, só aqueles que quisessem ir consultar ou tirar alguma dúvida sobre material, e aí eu atendia os grupos individualmente". Aurora, ao contrário dos outros docentes, aplica PBL no decorrer da disciplina toda, mesclando com algumas aulas expositivas.

$\mathrm{Na}$ aplicação na pós-graduação lato sensu, tanto Pedro quanto Tatiana afirmam utilizar uma média de 25 horas de um curso de 360 horas. Já Beatriz o aplica na pós-graduação stricto sensu, em um único caso que abrange o conteúdo todo trabalhado no semestre. Esses resultados demonstram que os docentes apresentam preocupação com o tempo e tipo de trabalho a ser desenvolvido, sendo este um dos fatores determinantes do sucesso, conforme apontado por Martins \& Frezatti (2015).

No que tange ao papel do docente durante a aplicação da metodologia, Pedro o vê como "um facilitador da interação entre esses grupos [de alunos, previamente separados para trabalhar em equipe]", que realiza a "parte mais de coordenação". Tal perspectiva converge com a de Tatiana: ela entende que o docente "tem mais o papel de orientador", contudo ressalta que "no caso da graduação [o papel do docente é o] de mostrar o caminho, [enquanto] na pós [é o] de evitar que eles se dispersem e comecem a [...] fugir do assunto". Aurora complementa afirmando que o docente "deve estar preparado e 
ser facilitador do aprendizado", tomar cuidado para se manter sempre atualizado na escolha dos casos e "ser capaz de perceber se as habilidades e atitudes estão sendo desenvolvidas nos seus alunos, além do conhecimento". Beatriz confessa ter se sentido excluída nas primeiras aplicações do método, mas que com o passar do tempo viu que o papel do professor, além de mediar discussões, é "analisar todos os grupos, ver se eles estão realizando os procedimentos de acordo com a indicação do material, até mesmo instigar alguma coisa entre eles". Com base no exposto pelos docentes, vê-se que para eles o professor transcende o papel de simples transmissor de conhecimentos e adota a postura defendida por Freire (1996). Segundo este autor, o professor deve ser capaz de criar possibilidades para a construção e a produção do conhecimento, adotando, assim, um papel de facilitador do processo de ensino-aprendizagem.

Os docentes foram questionados também sobre a seleção dos problemas trabalhados em sala de aula. Aurora, por utilizar a metodologia durante a disciplina toda, emprega dois tipos de problemas. No decorrer da primeira parte do semestre, a docente utiliza casos de ensino prontos que se relacionem com o conteúdo a ser trabalhado, e na segunda parte os alunos trazem um problema de seu cotidiano profissional para ser resolvido por seu grupo. Tatiana e Pedro costumam usar casos retirados de livros a respeito do conteúdo que está sendo trabalhado em sala de aula.

Pedro, apesar de utilizar casos retirados de livro, observa que "em algumas situações o texto era muito superficial na questão de elementos, então esgotava muito rápido o conceito que eu gostaria de explicar". O docente vai além e afirma que "com um caso um pouco mais complexo, com um nível de sofisticação um pouco maior - e isso não era minha expectativa no começo -, os alunos respondem melhor, mesmo não conhecendo todos os elementos daquele caso". Beatriz, além de utilizar os casos disponíveis em livros, adapta casos disponibilizados por periódicos e eventos acadêmicos, além de participar de um grupo de estudos que desenvolve casos para diversas áreas do conhecimento.

Dessa forma, vê-se a necessidade da criação de mais problemas para auxiliar os docentes a aplicarem a metodologia. Segundo Martins e Espejo (2015), os problemas a serem aplicados devem ser complexos, mal estruturados e sem respostas prontas, para incentivar o aluno a pensar não só na resolução do problema, mas vê-lo como um todo ao estruturá-lo para sua resolução. As autoras afirmam ainda que o problema deve promover um feedback para os alunos avaliarem sua própria eficiência durante a resolução.

Para finalizar esse bloco de perguntas, os participantes foram questionados a respeito da aprendizagem dos alunos e da avaliação. No que diz respeito a esta, os quatro participantes indicaram o uso de relatórios combinados a outros instrumentos avaliativos. Pedro utiliza a entrega do relatório aliada à observação dos grupos nos cursos de pós-graduação lato sensu, mas não usa a metodologia como forma de avaliação na graduação. Já Tatiana realiza a avaliação dos alunos por meio de uma apresentação, e Aurora aplica uma prova e solicita uma apresentação dos relatórios. A avaliação mais complexa é a realizada por Beatriz, que alia à entrega do relatório as observações, a apresentação, a autoavaliação e a avaliação dos pares.

Por fim, questionado sobre a aprendizagem dos alunos, Pedro aponta "uma mudança de postura deles, já que eles aparentemente se sentem mais motivados". A percepção de Beatriz vai ao encontro da de Pedro, e a mesma complementa: "a gente percebe diferenças inclusive na participação dos alunos, porque quando é uma aula que você tem o método tradicional tem alguns alunos que se acomodam e participam muito pouco; quando é em grupo, eu tive a percepção que alguns alunos que não participavam, na aula normal, nos grupos expunham mais as ideias deles, conseguiam trazer um auxílio para discussão melhor do que quando estavam em sala de aula em conjunto". Aurora destaca que seus alunos, além da postura mais ativa e de maior interesse pela disciplina, reportaram "um incremento na leitura. Outros disseram que nunca haviam cursado uma 
disciplina tão interessante, que lhes trouxesse esta visão nova".

Por fim, a experiência de Tatiana vai na contramão do exposto pelos outros docentes, pois segundo ela: "acho que na contábeis na graduação não foi eficiente [...], tanto que depois eles pediram pra eu dar aula e eu acabei ministrando aula a respeito do assunto depois e passando exercício". Contudo, a docente ressalta que a experiência pode não ter dado certo devido a dois fatores: a tecnicidade/especificidade do assunto e o perfil da turma. Tatiana afirma: "a gente foi muito infeliz na escolha do tema, pois ele é muito técnico, né? Ele tem pouca flexibilidade para discussão, é muito baseado na norma". Em relação ao perfil da turma, a docente pondera: "não adianta a metodologia ser ativa e os alunos serem passivos, ela tem que combinar com o perfil da turma".

\section{Considerações Finais}

$\mathrm{O}$ presente trabalho teve como objetivo apresentar a percepção docente a respeito da utilização da metodologia PBL como estratégia de ensino nos cursos de ciências contábeis. $\mathrm{O}$ foco no professor justifica-se, pois, como apontado por Martins e Espejo (2015), ele é um dos três elementos principais da metodologia, contudo são poucos os estudos que o abordam.

Com base nas entrevistas realizadas, percebe-se que existe uma falha na formação pedagógica do docente, resultado que corrobora estudos anteriores (ANDERE \& ARAUJO, 2008; SLOMSKI et al., 2014; LIMA et al., 2015). Os entrevistados foram unânimes ao dizer que conheceram o PBL somente após estarem atuando na docência. Isso justifica o fato da divergência de opiniões a respeito de qual é o papel do docente perante o PBL; essa confusão por parte do docente pode colocar em xeque os benefícios da utilização do método.

Os professores relataram uso do PBL na graduação e na pós-graduação, entretanto houve uma queixa com relação à inexistência de material didático de qualidade a ser utilizado nas aulas de PBL.

Por final, os entrevistados avaliam que a utilização do PBL ocasionou uma mudança de postura por parte dos discentes, que se demonstraram ativos no processo, o que demonstra que o método pode ser utilizado com benefícios nos cursos de contabilidade.

\section{Referências Bibliográficas}

ANDERE, M. A. \& ARAUJO, A. M. P. "Aspectos da Formação do Professor de Ensino Superior de Ciências Contábeis: uma Análise dos Programas de Pós-graduação". Revista Contabilidade \& Finanças-USP, vol. 19, n. 48, set.-dez. 2008, pp. 91-102.

ARAUJO, A. M. P.; FREGONESI, M. S. F. A.; SOARES, M. \& SLOMSKI, V. G. "Aplicação do Método Problem Based Learning (PBL) no de Curso de Especialização em Controladoria e Finanças". Congresso Internacional PBL, 2010.

ARAUJO, A. M. P. \& SLOMSKI, V. G. "Active Methods: an Analysis of Applications and Experiences in Brazilian Accounting Teaching". Creative Education, vol. 4, n. 12b, 2013, pp. 20-27.

BENJAMIN JUNIOR, V. \& CASA NOVA, S. P. C. "Teoria da Complexidade e Contabilidade: Estudo da Utilização da Aprendizagem Baseada em Problemas como Abordagem Complexa no Ensino de Contabilidade". 12 Congresso USP de Controladoria e Contabilidade, São Paulo-SP, 2012.

BERBEL, N. A. "As Metodologias Ativas e a Promoção da Autonomia de Estudantes". Semina: Ciências Sociais e Humanas, vol. 32, n. 1, 2011, pp. 25-40.

CAREGNATO, R. C. A. \& MUTTI, R. "Pesquisa Qualitativa: Análise de Discurso versus Análise de Conteúdo". Texto \& Contexto em Enfermagem, vol. 15, n. 4, 2006, pp. 679-84.

FARIAS. R. S. \& ARAUJO, A. M. P. "Percepção dos Professores de Contabilidade quanto aos Espaços Formativos para o Ofício da Docência no Brasil". Revista de Contabilidade e Organizações, vol. 10, n. 28, 2016, pp. 58-70.

FREIRE, P. Pedagogia da Autonomia: Saberes Necessários à Prática Educativa. São Paulo: Paz e Terra, 1996.

GRISHAM, J. W.; MARTINIUK, A. L.; NEGIN, J. \& WRIGHT, E. P. "Problem Based Learning (PBL) and Public Health An Initial Exploration of Perceptions of PBL in Vietnam". Asia-Pacific Journal of Public Health, vol. 27, n. 2, 2015, pp. 2019-2027.

LIMA, F. D. C., OLIVEIRA, A. C. L., ARAÚJO, T. S., \& MIRANDA, G. J. O choque com a realidade: dormi contador e acordei professor... REICE. Revista Iberoamericana sobre Calidad, Eficacia y Cambio en Educacion, vol. 13, n. 1, 2015, pp. 49-67.

MARIN, T. I. S.; LIMA, S. J. \& CASA NOVA. S. P C. "Formação do Contador: O que o Mercado Quer, É o que Ele Tem? Um Estudo sobre o Perfil Profissional 
dos Alunos de Ciências Contábeis da FEA-USP". Revista Contabilidade Vista e Revista, vol. 25, n. 2, 2014, pp. 59-83.

MARTINS, D. B. \& ESPEJO, M. M. S. B. Problem Based Learning - PBL no Ensino de Contabilidade. Guia Orientado para Professores e Estudantes da Nova Geração. São Paulo: Atlas, 2015.

MARTINS, D. B. \& FREZATTI, F. Problem-based Learning no Ensino em Contabilidade Gerencial: Experiências numa Instituição de Ensino Superior. In: CONGRESSO USP CONTROLADORIA E CONTABILIDADE, 15, 2015, São Paulo. Anais... São Paulo/SP: 2015.

MASETTO, M. T. Competência Pedagógica do Professor Universitário. São Paulo: Summus Editorial, 2012.

MITRE, S. M.; SIQUEIRA-BATISTA, R.; GIRARDI-DE-MENDONÇA, J. M.; MORAISPINTO, N. M.; MEIRELLES, C. A. B.; PINTOPORTO, G.; MOREIRA, T.; HOFFMANN, L. M. A. "Metodologias Ativas de Ensino-Aprendizagem na Formação Profissional em Saúde: Debates Atuais". Ciência \& Saúde Coletiva, vol. 13, 2008, pp. 2133-2144.

RIBEIRO, L. R. C. Aprendizagem Baseada em Problemas (PBL): Uma Implementação na Educação em Engenharia na Voz dos Atores. 203 f. Tese (Doutorado em Educação) - Faculdade de Educação, Universidade Federal de São Carlos, São Carlos, 2005.

RODRIGUES, E. D. A. \& ARAUjO, A. M. P. de. "O Ensino da Contabilidade: Aplicação do Método
PBL nas Disciplinas de Contabilidade em uma Instituição de Ensino Superior Particular". Revista de Educação, vol. 10, n. 10, 2007, pp. 166-176.

SIQUEIRA, J. R. M.; SIQUEIRA-BATISTA, R.; MORCH, R. B. \& SIQUEIRA-BATISTA, R. "Aprendizagem Baseada em Problemas: o Que os Médicos podem ensinar aos Contadores". Contabilidade Vista \& Revista, vol. 2, n. 3, 2009, pp. 101-125.

SLOMSKI, V. G.; LAMES, L.G.J.; LAMES, R.R. La Competência Didáctico Pedagógica del Profesor de Administración de Costos de un Curso de Ciencias Contables Ofrecido por un IES del Estado de São Paulo. In: CONGRESSO INTERNAGIONAL DE EDUCAÇÃO SUPERIOR - UNIVERSIDAD, 9, 2014, Havana - Cuba. Anais... Havana: 2014.

SOARES, M. A.; ARAUJO, A. D. \& LEAL, E. A. "Evidências Empíricas da Aplicação do Método Problem Based Learning (PBL) na Disciplina de Contabilidade Intermediária do Curso de Ciências Contábeis". Enanpad, Rio de Janeiro, 2008.

SOARES, M. A.; BOTINHA, R. A.; CASA NOVA, S. P. C.; SOARES, S. V.; BULAON, C. "Aprendizagem baseada em problemas (ABP) ou Problem-based learning (PBL): podemos contar com essa alternativa?". In: LEAL, E. A.; MIRANDA, G. J.; CASA NOVA, S. P. C. Revolucionando a Sala de Aula. Como Envolver o Estudante Aplicando as Técnicas de Metodologias Ativas de Aprendizagem. São Paulo: Atlas, 2017.

Publicado em 04/07/2018. 